\title{
Recent trends in lung cancer and its association with COPD: an analysis using the UK GP Research Database
}

\author{
*Victor A Kiria, Joan B Soriano ${ }^{b}$, George Visickc, Leonardo M Fabbrid \\ a PAREXEL International, PACE, London, UK \\ ${ }^{b}$ Fundación Caubet-Cimera Illes Balears, Program of Epidemiology and Clinical Research, CIMERA, Mallorca, Spain \\ ' GlaxoSmithKline R\&D, Worldwide Epidemiology, London, UK \\ ${ }^{\mathrm{d}}$ Department of Respiratory Diseases, University of Modena \& Reggio Emilia, Modena, Italy
}

Received 24th February 2009; revised version received 6th May 2009; accepted 20th May 2009; online 15th September 2009

\begin{abstract}
Background: The association between lung cancer and COPD has not been investigated in the primary care setting.

Method: We determined the recent trends of lung cancer in COPD patients in the UK during the period 1991-2004, by investigating the population aged 45 and over in the General Practice Research Database.

Results: The annual-incidence rates of lung cancer per 10,000 person-years were at least four-fold higher in patients with prior COPD (increasing from 45 to 64 in men; 29 to 48 in women) compared with the general population (from 10 to 15 in men; 5 to 10 in women). These lung cancer trends had significant annual increases that were similar in men (5\%) and in women (5.5\%) with prior COPD; in contrast, the annual increases of lung cancer incidence rates in the general population differed by gender, being $4 \%$ in men but double in women (8\%). The three-year survival for lung cancer patients among those with prior COPD was almost half that of the general population (15\% versus 26\%; $\mathrm{p}<0.01)$ and the highest mortality was observed in men aged 45-64 (83.79 per 100 person-years; $95 \% \mathrm{Cl}$ : 69.66-97.92).
\end{abstract}

Conclusion: These results support the association of COPD and lung cancer observed in other settings.

(C) 2010 Primary Care Respiratory Society UK. All rights reserved.

VA Kiri et al. Prim Care Resp J 2010; 19(1): 57-61.

doi:10.4104/pcrj.2009.00048

Keywords COPD, epidemiology, observational, quantitative, lung cancer

\section{Introduction}

Associations between lung cancer and acquired lung diseases that obstruct airflow including chronic obstructive pulmonary disease (COPD) have been noted, although a recent review has highlighted the many issues that await resolution after more than 60 years of research on this topic. ${ }^{1}$ Nevertheless, a substantial body of evidence suggests that COPD or impaired lung function is associated with the occurrence of lung cancer. ${ }^{2-4}$ Although cigarette smoking is the principal cause of both COPD and lung cancer, many studies have found evidence of the role of COPD in the development of lung cancer, independent of smoking., 5-10 One of these studies estimated the prevalence of COPD in lung cancer patients as between $50-65 \%$. ' At values of forced expiratory volume in one second $\left(\mathrm{FEV}_{1}\right)$ lower than $70 \%$ predicted and after adjusting for confounders such as smoking, the excess risk of lung cancer due to COPD was estimated at 2.23 in men and 3.94 in women. Studies have also shown that the risk of developing lung cancer does not immediately disappear after smoking cessation - perhaps explaining why, in the USA, lung cancer now occurs in as many former smokers as current smokers. ${ }^{11}$

In a landmark clinical and molecular study, the expression of a number of putative oncogenes and tumour suppressor genes in the airway epithelial cells of smokers did not return to normal for decades after smoking cessation, although many others (especially the antioxidant and drugmetabolising genes) did so within two years. ${ }^{12}$ The same study suggests that there may also be a gene expression profile that is characteristic of COPD, having identified a number of genes

\footnotetext{
* Corresponding author: Professor Victor A Kiri, PAREXEL International, PACE, The Quays, 101-105 Oxford Rd, Uxbridge, London, UB8 1LZ, United Kingdom. Tel: +44 (0)1895 614760 Fax: +44 (0)1895614277 E-mail: victor.kiri@PAREXEL.com
} 
whose expression levels correlate in a negative or positive fashion with $\mathrm{FEV}_{1}$ that are not altered in subjects with lung cancer. The reason why some smokers develop COPD while others do not remains unclear, as is the reason why some smokers are free of both COPD and lung cancer.

The UK General Practice Research Database (GPRD), an automated database that covers about $5 \%$ of the population, has the potential to help us better define the epidemiology of lung cancer in the UK general population as well as among those people with COPD. Lung cancer has been investigated in two previous studies using the GPRD: one examined patients with cryptogenic fibrosing alveolitis and its association with lung cancer; ${ }^{13}$ the other was a case-control study that explored whether non-steroidal anti-inflammatory drug treatment protects against the commoner cancers in the UK. ${ }^{14}$ Furthermore, previous studies have also described the clinical epidemiology of COPD using the GPRD in terms of trends of prevalence and incidence in the UK..$^{15-16}$

The aim of our study was to describe the relationship between lung cancer and COPD in the UK primary care setting. We aimed to determine the trends in annual incidence of lung cancer in individuals already diagnosed with COPD and in those from the general population over a 15year period in the GPRD.

\section{Methods}

The GPRD database has been described elsewhere. ${ }^{17} \mathrm{It}$ is a large, automated network of general practices in the UK that continues to provide a unique and continuous source of information on the overall health of the general population. It is therefore a valuable data source for the identification of incidence and prevalence of major diseases, analysis of treatment patterns and outcome for specific diseases, variations in prescribing patterns, and adverse reactions to drugs, among others. A growing number of studies conducted in the GPRD database have been widely reported elsewhere, and the GPRD update as of December 2006 was used in this study. ${ }^{18-21}$ This study was conducted within a research protocol approved by the Independent Scientific Advisory Committee (ISAC) of the GPRD.

\section{Case definitions}

The study period for inclusion was between 1st January 1991 and 31st December 2004, and the survival analyses were extended up to 2006. Validated OXMIS/READ codes in the GPRD (see http://www.gprd.com) were used to identify patients with incident diagnosis of COPD and/or lung cancer during the study period. Furthermore, only patients aged 45 years and older at diagnosis, from practices whose data were classified as 'up to standard' in the GPRD, were included. We excluded patients with asthma codes identified at any time before COPD, and anyone with cystic fibrosis.

\section{Study design}

Two cohorts were determined. We defined a cohort of GPRD participants who were at risk of lung cancer at the start of our study period, and another cohort of GPRD participants with COPD who were similarly at risk of lung cancer. Patients with a prior lung cancer diagnosis before cohort entry were excluded in both cohorts because of our interest in the incidence (i.e. development) of lung cancer in the COPD and in the general population cohorts. In each cohort, the individual's longitudinal medical records were reviewed, and for each year of the study period we identified patients who were diagnosed with lung cancer for the first time (i.e. incident cases).

\section{Statistics}

In the COPD cohort (i.e. to estimate lung cancer incidence in COPD), the date of the first OXMIS/READ code identifying incident physician-diagnosed COPD was used as time zero in the analysis. As COPD is a serious condition that needs regular medical management, an individual was considered censored if no GP contact was recorded 12 months after his/her last visit or medical contact - as was done in previous studies using the database. ${ }^{18-21}$ In a similar way, censoring was applied when a patient either left the practice or died.

Annual lung cancer incidence rates per 10,000 patients (as 5-year moving averages) and mortality rates of lung cancer per 100 person-years were estimated by gender, calendar year from 1991 to 2004, and age, using standard techniques. $^{22}$ Log linear models were used to compare mortality distributions by gender and age.

\section{Results}

During the period 1st January 1991 to 31st December 2004, a total of 18,077 patients with incident diagnosis of lung cancer were identified in the GPRD from a population of $4,688,416$ persons aged 45 and older who were free of the

\begin{tabular}{|c|c|c|}
\hline & Lung cancer & $\begin{array}{l}\text { Lung cancer in those } \\
\text { with prior COPD }\end{array}$ \\
\hline Number & 18,077 & 1,260 \\
\hline $45-64$ years, $n(\%)$ & $4,783(26.5)^{*}$ & $204(16.2)$ \\
\hline 64+ years, n (\%) & $13,294(73.5)^{*}$ & $1,056(83.8)$ \\
\hline Female, n (\%) & $7,262(40.2)^{*}$ & $463(36.8)$ \\
\hline $\begin{array}{l}\text { Mean age at } \\
\text { diagnosis (SD) }\end{array}$ & $71.1(10.6)^{\star}$ & $72.9(8.7)$ \\
\hline
\end{tabular}




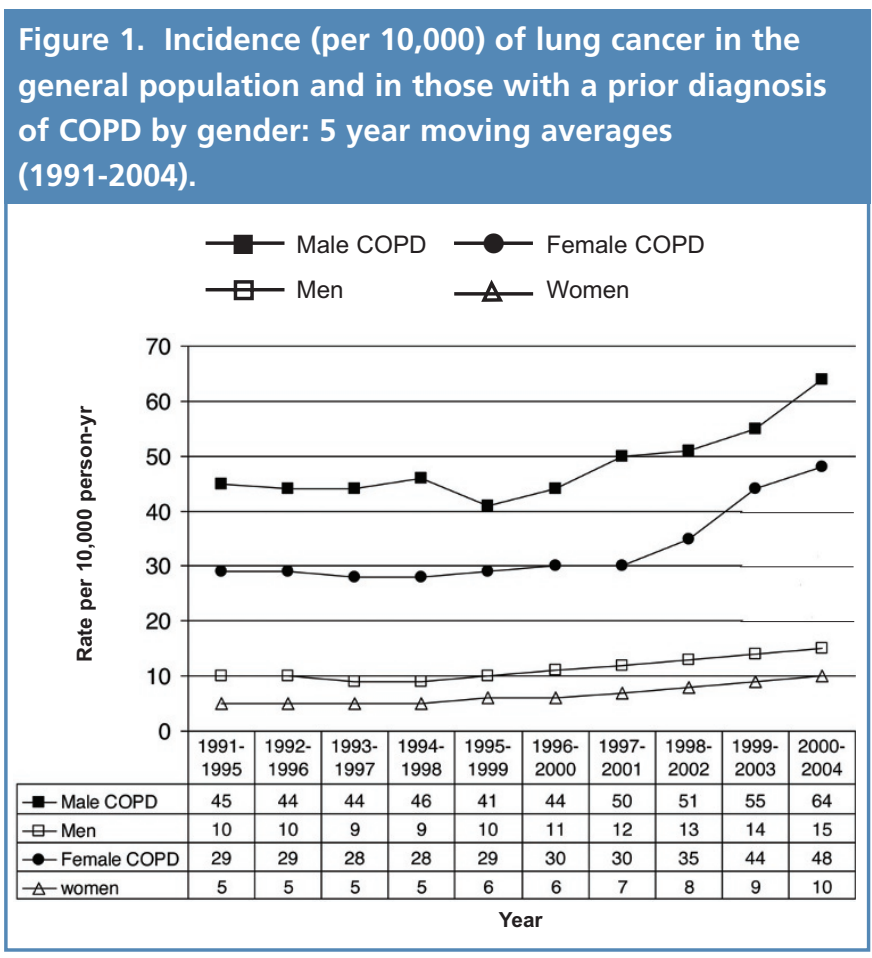

disease at the study start. Similarly, we identified 1,260 patients with lung cancer among those previously diagnosed with COPD (Table 1). The total number of incident-diagnosed COPD patients in the period was 42,188 .

Women represented $40 \%$ of all lung cancer patients, and this percentage was slightly but significantly less among those with previous COPD (36.8\%) ( $p=0.02)$. Among all patients, the average age at diagnosis of lung cancer was 071.1 $(S D=10.6)$ and just over $26 \%$ of these were under 65 years of age. Among those with a previous diagnosis of COPD, average age was slightly but significantly older than in the general population at 72.9 years ( $S D=8.7)$, and significantly fewer were under 65 years of age (i.e. 16.2\%; $p<0.0001$ ).

Annual incidence rates of lung cancer increased significantly over the study period in the general population from 10 to 15 per 10,000 in men and from 5 to 10 per
Figure 2. Three-year survival of lung cancer patients in the general population and in those with a prior diagnosis of COPD.

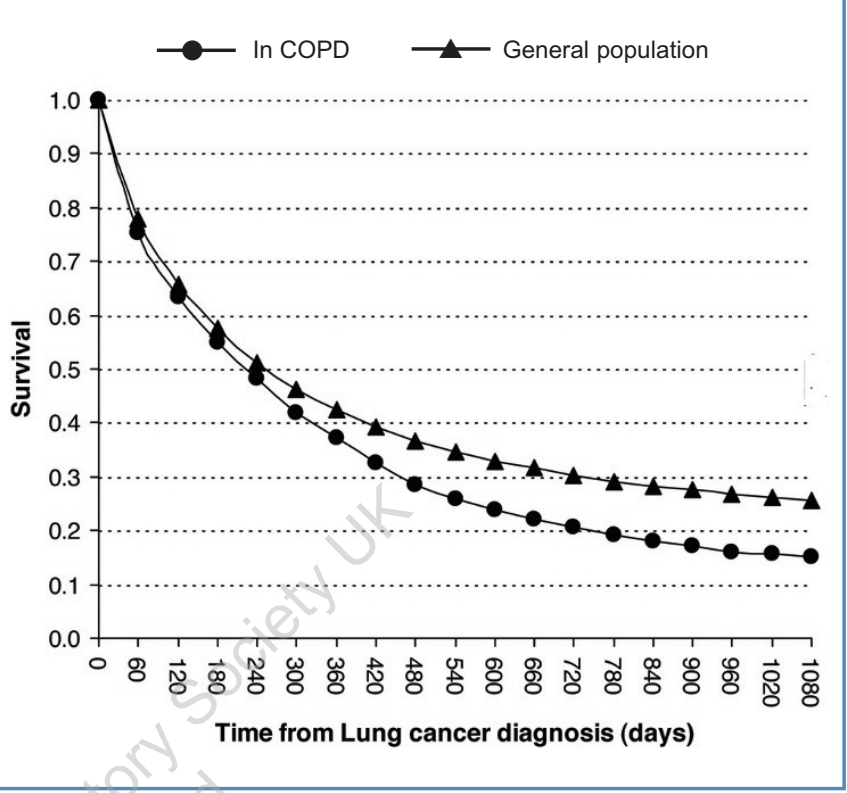

10,000 in women (Figure 1). Among those with a prior diagnosis of COPD, annual incidence rates were more than four-fold and five-fold higher than in the general population in men and women, respectively, increasing from 45 to 64 per 10,000 in men and from 29 to 48 per 10,000 in women. These trends indicated a narrowing of the gender gap in annual incidence among the general population $(4.4 \%$ in men compared with $8.2 \%$ in women), but we found no gender differences in the average annual increase of lung cancer in those with prior COPD diagnosis $(5 \%$ in men compared with $5.5 \%$ in women).

Figure 2 shows that, although the survival of lung cancer patients in the first three years since diagnosis was very low, survival was much lower among those with a prior diagnosis of COPD. Only about $15 \%$ of those with prior COPD diagnosis survived for three years compared with nearly $26 \%$ among all

Table 2. Mortality rates (per 100 person-years) in lung cancer patients, and of those with a prior diagnosis of COPD.

Lung cancer
Lung cancer in those

with prior COPD

\begin{tabular}{|c|c|c|c|}
\hline Mean age at death (SD) & 72. $5(10.4)$ & 73. $9(8.7)$ & \\
\hline \multicolumn{4}{|c|}{ Mortality rates (per 100 person-years) and 95\% C.I. } \\
\hline Female & $40.88(39.77,41.99)$ & $75.13(67.31,82.95)^{*}$ & $1.84(1.65,2.05)^{*}$ \\
\hline Male & $39.56(38.69,40.43)$ & $75.17(69.33,81.01)^{*}$ & $1.90(1.75,2.06)^{*}$ \\
\hline $45-64$ & $64.47(62.14,66.80)$ & $83.79(69.66,97.92)^{*}$ & $1.30(1.09,1.54)^{*}$ \\
\hline $65+$ & $36.13(35.43,36.83)$ & $73.95(69.00,78.90)^{*}$ & $2.05(1.91,2.19)^{*}$ \\
\hline
\end{tabular}


lung cancer patients. Indeed, mortality rates were significantly higher in those with prior COPD (rate ratios of $1.84 ; 95 \% \mathrm{Cl}$ : 1.65-2.05 in females and 1.90; 95\% Cl: 1.75-2.06 in men) and among the sub-group aged 65 or older, in which rates were twice those observed in the whole group (Table 2).

Mortality rates were similar among men and women with prior COPD (75.17; 95\% Cl: 69.33-81.01 versus 75.13; 95\% $\mathrm{Cl}: 67.31-82.95)$, as well as in the general population, (39.56; 95\% Cl: $38.69-40.43$ versus 40.88.13; $95 \% \mathrm{Cl}$ : 39.7741.99), respectively.

\section{Discussion}

Over the 14-year period (1991-2004) evaluated in this study, the incidence of lung cancer increased significantly, both in men and in women. Annual incidence rates of lung cancer were at least four-fold higher in patients with prior COPD when compared with the general population. Incidence trends of lung cancer indicated a significant narrowing of the gender gap in the general population, but among those with COPD there was no noticeable change in the gender gap. Although the three-year survival from diagnosis of lung cancer was very low, it was considerably lower in those with a prior COPD diagnosis. Lung cancer is more common in patients aged 65 and older - and among those with a prior diagnosis of COPD, lung cancer is diagnosed at an even later age.

COPD and lung cancer share many common pathophysiological features, and COPD patients are often considered at high risk of developing lung cancer. ${ }^{23}$ In a prospective study, the risk of developing lung cancer was found to be associated with age, smoking and ventilatory status. ${ }^{24}$ Primarily, the main risk factor for the onset of both diseases is cigarette smoking, but they probably also share a common familial component and environmental risk factors other than smoking. ${ }^{25}$ Some common elements in the pathogenesis of COPD and lung cancer include genetic predisposition (p53, Rb, K-ras), peptides and endopeptidases (bombesin-like), inflammation and oxidants (cigarette smoking), and dysregulation of growth factor expression, ${ }^{26}$ among others.

In a clinical review of a case series of 966 lung cancer patients admitted over a period of 24 years in Japan, 73 patients (7.5\%) were diagnosed as having COPD; of these, 68 (93.2\%) were men, and in 43 cases (58.9\%) the tumours were squamous cell carcinomas. ${ }^{27} \mathrm{~A}$ recent case-control study also conducted in Japan involving COPD patients matched to patients with benign respiratory diseases (as regards age, gender and smoking history) estimated the relative risk of cancer incidence as 2.32 (95\% C.I: 1.24-4.27); ${ }^{28}$ the study reported the most common cancers in COPD patients as being in the lung (18 cancers), the head and neck (15 cancers), and the urinary tract (6 cancers). The authors concluded that physicians should be alert to the development of malignancies in COPD patients, in the lung and other locations, so as to detect them at an early stage and administer proper treatment.

Another study also found an association between lung cancer and prior COPD which was assessed by lung function measurement. ${ }^{29}$ The authors studied adult participants in the US First National Health and Nutrition Examination Survey, who had up to 22 years of follow-up. Subjects were classified as having moderate to severe obstructive lung disease at baseline if the ratio $\mathrm{FEV}_{1}$ to forced vital capacity (FVC) was less than 0.70 and the $\mathrm{FEV}_{1}$ was less than $80 \%$ of the predicted value. Incident cases of lung cancer during the follow-up period were studied. A total of 113 (2.0\%) lung cancers occurred in the 5,402 adults in the cohort. In the proportional hazards model which was adjusted for age, gender, race, education, smoking status, and duration as well as intensity of smoking, the presence of moderate to severe obstructive lung disease was found to be associated with a higher risk of incident lung cancer (hazard ratio, 2.8; 95\% Cl: 1.8-4.4).

Although our study may be the first to find similar evidence of the association between lung cancer and COPD in the primary care setting, and although it includes a much longer follow-up and duration than any other, it has some notable limitations. Implementation of spirometry in primary care is not universal in the UK and elsewhere, and many GPs often only rely on a clinical diagnosis of chronic bronchitis and emphysema without performing spirometry - which is contrary to international COPD guidelines which require post-bronchodilator spirometry for the diagnosis and staging of COPD. ${ }^{30}$ The GPRD data lacked quantitative information on tobacco consumption, and lung cancer pathology is not systematically recorded. Consequently, we have not addressed the role of smoking as a confounding factor in the association found between COPD and lung cancer incidence. Nevertheless, both lung cancer and COPD have been previously studied in the GPRD and the findings reported. . $^{13-16,18-21}$ Indeed, the higher risk of lung cancer we found among those with COPD aged 65 or older has also been reported elsewhere. ${ }^{29}$ In a large, recent study, Wilson et al., ${ }^{31}$ using CT scan together with spirometry to search for emphysema and lung cancer in 3,638 smokers, were intrigued to find absence of a doseresponse relationship between smoking intensity and lung cancer among those with moderate to severe emphysema - a finding which has led to the hypothesis that COPD patients may have some host or susceptibility factors that protect them from developing cancer in general (having taken 30 or more years of exposure to tobacco to develop COPD), whereas in those who are more susceptible to developing cancer, lung cancer is likely to be diagnosed before COPD.

Although further research is needed to add evidence in this area, we conclude that our real-life data from UK primary care support the hypothesis that COPD is associated with lung cancer incidence. 


\section{Acknowledgements}

We would like to thank Professors Jorgen Vesbo and Neil Pride for important scientific contributions.

\section{Conflict of interest statement}

Victor A Kiri and Joan B Soriano are former employees of GlaxoSmithKline R\&D. George T Visick is currently employed by GlaxoSmithKline R\&D. Leonardo M Fabbri has served as consultant to GlaxoSmithKline, Altana Pharma, AstraZeneca, Boehringer Ingelheim, Chiesi Farmaceutici, Merck Sharp \& Dohme, Novartis, Roche and Pfizer. There is no other conflict of interest in this study.

\section{References}

1. Alberg AJ, Samet JM. Epidemiology of lung cancer. Chest 2003;123(1 Suppl): 21S-49S. http://dx.doi.org/10.1378/chest.123.1_suppl.21S

2. Tockman, MS Other host factors and lung cancer susceptibility. Samet, JM eds. Epidemiology of lung cancer 1994, 397-412 Marcel Dekker New York, NY.

3. Lange P, Nyboe J, Appleyard M, Jensen G, Schohr P. Ventilatory function and chronic mucus hypersecretion as predictors of death from lung cancer. Am Rev Respir Dis 1990;141:613-17.

4. US Department of Health, and Human Services (USDHHS). The health consequences of smoking: chronic obstructive lung disease; a report of the Surgeon General. 1984 US Government Printing Office Washington, DC.

5. Kennedy TC, Proudfoot SP, Franklin WA, et al. Cytopathological analysis of sputum in patients with airflow obstruction and significant smoking histories. Cancer Res 1996;56:4673-8.

6. Diez-Herranz A. COPD and lung cancer: practical implications. Arch Broncopneumol 2001;37(5):240-7.

7. Prindiville SA, Byers T, Hirsch FR, et al. Sputum cytological atypia as a predictor of incident lung cancer in a cohort of heavy smokers with airflow obstruction. Cancer Epidemiol, Biomarkers \& Prev 2003;12:987-93.

8. Wasswu-Kintu S, Gan WQ, Man SF, Pare PD, Sin DD. Relationship between reduced forced expiratory volume in one second and the risk of lung cancer: a systematic review and meta-analysis. Thorax 2005;60:570-5. http://dx.doi.org/10.1136/thx.2004.037135

9. Brody JS, Spira A. State of the art. Chronic obstructive pulmonary disease, inflammation, and lung cancer. Proc Am Thorac Soc 2006;3:535-7. http://dx.doi.org/10.1513/pats.200603-089MS

10. Purdue MP, Gold L, Järvholm B, Alavanja MC, Ward MH, Vermeulen R. Impaired lung function and lung cancer incidence in a cohort of Swedish construction workers. Thorax 2007;62:51-6. http://dx.doi.org/10.1136/thx.2006.064196

11. Proctor RN. Tobacco and the global lung cancer epidemic. Nat Rev Cancer 2001;1:82-6. http://dx.doi.org/10.1038/35094091

12. Spira A, Beane J, Shah V, et al. Effects of cigarette smoke on the human airway epithelial cell transcriptome. Proc Natl Acad Sci USA 2004;101:10143-8. http://dx.doi.org/10.1073/pnas.0401422101

13. Hubbard R, Venn A, Lewis S, Britton J. Lung cancer and cryptogenic fibrosing alveolitis. A population-based cohort study. Am J Respir Crit Care Med 2000;161:5-8.

14. Langman MJ, Cheng KK, Gilman EA, Lancashire RJ. Effect of anti-inflammatory drugs on overall risk of common cancer: case-control study in general practice research database. BMJ 2000;320:1642-6. http://dx.doi.org/ 10.1136/bmj.320.7250.1642

15. Pride NB, Soriano JB. Chronic obstructive pulmonary disease in the United Kingdom: trends in mortality, morbidity, and smoking. Curr Opin Pulm Med 2002; 8:95-101.

16. Hansell A, Hollowell J, Nichols T, et al. Use of the General Practice Research Database (GPRD) for respiratory epidemiology: a comparison with the 4th Morbidity Survey in General Practice (MSGP4). Thorax 1999;54:413-19.

17. Nazareth I, King M, Haines A. Rangel L. Myers S. Accuracy of diagnosis on general practice computer system. BMJ 1993;307:32-4. http://dx.doi.org/ 10.1136/bmj.307.6895.32

18. Soriano JB, Maier WC, Egger $P$, et al. Recent trends of physician-diagnosed COPD in women and men in the UK. Thorax 2000;55:789-94. http://dx.doi.org/10.1136/thorax.55.9.789

19. Soriano JB, Vestbo J, Pride NB, Kiri V, Maier WC. Survival of COPD patients after regular use of fluticasone propionate and salmeterol in primary care in the UK. Eur Respir J 2002;20:819-25. http://dx.doi.org/10.1183/09031936.02.00301302

20. Kiri VA, Bettoncelli $G$, Testi $R$, et al. Inhaled corticosteroids are more effective in COPD patients when used with LABA than with SABA. Respir Med 2005; 99:1115-24. http://dx.doi.org/10.1016/j.rmed.2005.02.018

21. Kiri VA, Pride NB, Soriano JB, et al. Inhaled corticosteroids in chronic obstructive pulmonary disease: results from two observational designs free of immortal time bias. Am J Respir Crit Care Med 2005;172:460-4. http://dx.doi.org/10.1164/rccm.200502-2100C

22. Soriano JB, Kiri VA, Maier WC, Strachan D. Increasing prevalence of asthma in UK primary care during the 1990s. Int J Tuberc Lung Dis 2003;7:415-21.

23. Skillrud DM, Offord KP, Miller RD. Higher risk of lung cancer in chronic obstructive pulmonary disease. A prospective, matched, controlled study. Ann Intern Med 1986;105:503-07.

24. Tockman MS, Anthonisen NR, Wright EC, Donithan MG. Airways obstruction and the risk for lung cancer. Ann Intern Med 1987;106:512-18.

25. Cohen BH, Diamond EL, Graves CG, et al. A common familial component in lung cancer and chronic obstructive pulmonary disease. Lancet 1977;2:523-26. http://dx.doi.org/10.1016/S0140-6736(77)90663-8

26. Chronic Obstructive Lung Disease, NF Voelkel \& W MacNee Eds. BC Dekker Inc; Hamilton: 2002

27. Kurishima K, Satoh $H$, Ishikawa $H$, et al. Lung cancer patients with chronic obstructive pulmonary disease. Oncol Rep 2001;8:63-5.

28. Nakayama M, Satoh $H$, Sekizawa K. Risk of cancers in COPD patients. Chest 2003;123:1775-6. http://dx.doi.org/10.1378/chest.123.5.1775-a

29. Mannino DM, Aguayo SM, Petty TL, Redd SC. Low lung function and incident lung cancer in the United States: data From the First National Health and Nutrition Examination Survey follow-up. Arch Intern Med 2003;163:1475-80.

30. Pauwels RA, Buist AS, Calverley PM, Jenkins CR, Hurd SS. Global Strategy for the Diagnosis, Management, and Prevention of Chronic Obstructive Pulmonary Disease. NHLBIMHO Global Initiative for Chronic Obstructive Lung Disease (GOLD) workshop summary. Am J Respir Crit Care Med 2001;163:1256-76.

31. Wilson DO, Weissfeld JL, Balkan A, et al. Association of Radiographic Emphysema and Airflow Obstruction with Lung Cancer. Am J Respir Crit Care Med 2008;178:738-44. http://dx.doi.org/10.1164/rccm.200803-4350C

Available online at http://www.thepcrj.org 